$\mathrm{R}(\mathrm{B}) 3$; comparable to $\mathrm{T}(2 ; 3) 31616,607)$, moderately (for example, $\mathrm{R}(\mathrm{B}) 13$ ), or weakly (for example, $\mathrm{R}(\mathrm{B}) 4, \mathrm{R}(\mathrm{B}) 8$ ), and they were used to construct $C b x^{1} / \mathrm{R}(+)$ strains for analysis. In all of the $\mathrm{R}(+) / \mathrm{OR}$ heterozygotes we studied, each of the $U b x$ genes produced half of the $U b x$ RNA in both wing and haltere discs (data not shown). As described above, the $+U b x$ gene produces approximately $20 \%$ of the $U b x$ RNA in $C b x^{I} /+$ wing discs, and transvection-suppressing rearrangements reduce the total level of Ubx RNA in wing discs (Fig. 2). Surprisingly, the proportion of Ubx RNA derived from the + chromosome did not change significantly in any of the $\mathrm{R}(+) / C b x^{1}$ heterozygous wing discs (Fig. 3). This indicates that the rearrangements reduce $U b x$ expression from both homologues but do not eliminate transactivation specifically.

Our results show that the $C b x^{l}$ mutation activates $U b x$ expression in the wing disc on both homologues, confirming the prediction that regulatory elements can function in trans (summarized in Fig. 4). Wing disc expression induced by $C b x^{l}$ was sensitive to $z$ function and to chromosome asynapsis, observations that are consistent with previous proposals based on either phenotypic or molecular assays ${ }^{2,17,18}$. However, we found an unexpected difference between the mechanisms through which the $z^{a}$ mutation and chromosome rearrangements affect expression. Although chromosome rearrangements and $z^{a}$ have essentially indistinguishable phenotypic consequences, namely, suppression of the $C b x$ phenotype, only $z^{a}$ specifically disrupts trans-activation. Unexpectedly, chromosome rearrangements reduced expression from both homologues. These results suggest that, in normal wildtype flies, chromosome synapsis enhances expression of the $U b x$ genes on both homologues, implying that association between homologous chromosomes has a general enhancing effect on transcription. We presume that the systems in Drosophila in which transvection has been observed ${ }^{1-9}$ are those in which gene expression levels can be measured with particular sensitivity. Transvection may therefore provide a useful means of studying the interactions between homologous chromosomes that can subtly influence gene expression. Our finding that interactions between homologous chromosomes seem to enhance expression levels from both chromosomes has many possible implications. In particular, we note that gross chromosome rearrangements, such as translocations, could give rise to global reductions in gene expression on the affected chromosomes. They could therefore contribute to disease states associated with haplo-insufficiency and cancer, and could modulate fitness during speciation.

Received 23 February; accepted 15 May 1996

1. Lewis, E. B. Am. Nat. 88, 225-239 (1954).

2. Kornher, J. S. \& Brutlag, D. Cell 44, 879-883 (1986).

3. Gelbart, W. M. Proc, natn. Acad. Sci. U.S.A. 79, 2636-2640 (1982).

4. Babu, P. \& Bhat, S. in Developmental and Neurobiology of Drosophila (eds Siddiqi, O., Babu, P. Hall, L. \& Hall, J.) 35-40 (Plenum, New York, 1980)

5. Jack, J. W. \& Judd, B. H. Proc. natn. Acad. Sci. U.S.A. 76, 1368-1372 (1979)

6. Ashburner, M. Nature 214, 1159-1160 (1967).

7. Geyer, P., Green, M. M. \& Corces, V. G. EMBO J. 9, 2247-2256 (1990).

8. Dreesen, T. D., Henikoff, S. \& Loughney, K. Genes Dev. 5, 331-340 (1991)

9. Leiserson, W. M., Bonini, N. M. \& Benzer, S. Genetics 138, 1171-1179 (1994).

10. Judd, B. H. Cell 53, $841-843(1988)$

11. Tartoff, K. D. \& Hennikoff, S. Cell 65, 201-203 (1991).

12. Muller, H. P. \& Schaffner, W. Trends Genet. 6, 300-304 (1990)

13. Lewis, E. Nature 276, 565-570 (1978).

14. Goldsborough, A. S. \& Komberg, T. B. Proc. natn. Acad. Sci. U.S.A. 91, 12696-12700 (1994).

15. White, R. H. \& Wilcox, M. Nature 318, 567-569 (1985).

16. Gelbart, W. M. \& Wu, C.-T. Genetics 102, 179-189 (1982).

17. Zachar, Z., Chapman, C. H. \& Bingham, P. M. Cold Spring Harb. Symp. quant. Biol. 50, 337 346 (1985).

18. Castelli-Gair, J. E., Micol, J.-L. \& García-Bellido, A. Genetics 126, 177-184 (1990).

ACKNOWLEDGEMENTS. We thankI. Herskowitz C. Schwartz G. Morata, P. Therond and S. Cohen for suggestions; B. Holley for technical assistance; and E. Lewis, M. Green, G. Morata and K. Matthews suggestions; B. Holley for technical assistance; and E. Lewis, M. Green, G. Morat
for providing stocks. This work was funded by a grant from the NIH to T.B.K.

CORRESPONDENCE and requests for materials should be addressed to T.B.K. (e-mail: tomk@cgl.ucsf.edu).
ERRATA

\section{Non-chondritic platinum-group element ratios in the Earth's mantle}

\author{
L. Pattou, J. P. Lorand \& M. Gros
}

Nature 379, 712-715 (1996)

THE date of submission of this Letter for publication was given incorrectly as 16 March 1994; this date should have been 25 September 1995.

\section{A neural basis for lexical retrieval}

\section{Hanna Damasio, Thomas J. Grabowski, Daniel Tranel, Richard D. Hichwa \& Antonio R. Damasio}

Nature 380, 499-505 (1996)

AN ambiguity was introduced during editing into the opening sentence of the heading of this Article. This should read "Two parallel studies, one conducted in neurological patients with brain lesions, the other using positron emission tomography in normal individuals, indicate that the normal process of retrieving words that denote concrete entities depends in part on multiple regions of the left cerebral hemisphere, located outside the classic language areas."

\section{A mechanism for regulation of the adhesion-associated protein tyrosine kinase pp125 ${ }^{\mathrm{FAK}}$}

\section{Alan Richardson \& Thomas Parsons}

Nature 380, 538-540 (1996)

FIGURE 1, panel $i$, which was accidentally omitted from this Letter during the page-make-up process, is presented below. This figure shows the number of cells spread on fibronectin after $20 \mathrm{~min}$.

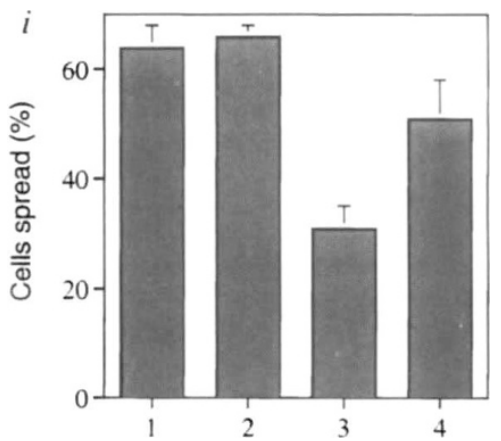

